\title{
Sustainable and Resilient Infrastructure
}

\section{A system-of-systems framework for exploratory analysis of climate change impacts on civil infrastructure resilience}

\section{Ali Mostafavi}

To cite this article: Ali Mostafavi (2018): A system-of-systems framework for exploratory analysis of climate change impacts on civil infrastructure resilience, Sustainable and Resilient Infrastructure, DOI: $10.1080 / 23789689.2017 .1416845$

To link to this article: https://doi.org/10.1080/23789689.2017.1416845

Published online: 07 Jan 2018.

Submit your article to this journal $\sqsubset$

Q View related articles ๘

View Crossmark data $\subset$ 


\title{
A system-of-systems framework for exploratory analysis of climate change impacts on civil infrastructure resilience
}

\author{
Ali Mostafavi \\ Zachry Department of Civil Engineering, Texas A\&M University, College Station, Texas
}

\begin{abstract}
Climate change has various chronic and acute impacts on civil infrastructure systems (CIS). A longterm assessment of resilience in CIS requires understanding the transformation of CIS caused by climate change stressors and adaptation decision-making behaviors of institutional agencies. In addition, resilience assessment for CIS includes significant uncertainty regarding future climate change scenarios and subsequent impacts. Thus, resilience analysis in CIS under climate change impacts need to capture complex adaptive behaviors and uncertainty in order to enable robust planning and decision-making. This paper presents a system-of-systems (SoS) framework for abstraction and integrated modeling of climate change stressors, physical infrastructure performance, and institutional actors' decision-making processes. The application of the proposed SoS framework is shown in an illustrative example related to the impacts of sea level rise and subsequent saltwater intrusion on a water system. Through the use of the proposed SoS framework, various attributes, processes, and interactions related to physical infrastructure and actor's decision-making were abstracted and used in the creation of a computational simulation model. Then, the computational model was used to simulate various scenarios composed of sea level rise and adaptation approaches. Through an exploratory analysis approach, the simulated scenario landscape was used to identify robust adaptation pathways that lead to a greater system resilience under future uncertain sea level rise. The results of the illustrative example highlight the various novel capabilities of the SoS framework: (i) abstraction of various attributes and processes that affect the long-term resilience of infrastructure under climate change; (ii) integrated modeling of CIS transformation based on simulating the adaptive decision-making processes, physical infrastructure performance, and climate change impacts; and (iii) exploratory analysis and identification of robust pathways for adaptation to climate change impacts.
\end{abstract}

\section{ARTICLE HISTORY}

Received 18 January 2017

Accepted 28 November 2017

\section{KEYWORDS}

Infrastructure; resilience; complex adaptive systems; climate change; adaptation; robust decision-making; simulation

\section{Introduction}

Dealing with climate change impacts is one of the major challenges of the twenty-first century. For example, hurricanes and storm surge events have become stronger over the past 30 years as a result of climate change impacts. These phenomena can have catastrophic impacts on coastal communities and result in coastal erosion, destruction of civil infrastructure systems (CIS), and catastrophic saltwater contamination of the water supply. Given the significance of CIS in economic growth, human well-being, and protection of communities against natural disasters, enhancing the resilience of CIS is one of the grand challenges facing engineers and policy-makers (Heller, 2001; O'Rourke, 2007). In particular, climate change is a major driver of changes in the socio-environmental conditions surrounding CIS. Climate change affects the resilience of
CIS in various ways: (i) changes in temperature and precipitation affecting the erosion of physical networks, (ii) population displacement affecting the demand on networks, (iii) changes in the priorities of agencies and subsequent allocation of limited resources, and (iv) increased frequency and magnitude of extreme events (e.g. floods) leading to a greater exposure of networks to risks (Chappin $\&$ van der Lei, 2014; Koetse \& Rietveld, 2009). In the context of climate change impacts, infrastructure resilience is the ability of coupled human-infrastructure systems to adapt and transform internal feedback processes, to cope with chronic or 'surprise' stressors, and recover from disruptions. Climate change, directly and indirectly, affects the performance of physical assets. For instance, the physical condition of a pavement network may be directly affected by the increased number of freeze-thaw cycles induced by climate change. In addition, climate change 
may stimulate changes in behaviors of infrastructure users and institutional agencies which in turn affect the physical condition of assets. In addition, institutional agencies adapt their decision-making and behaviors as they learn about the impacts of climate change on physical networks. This includes changes in policy objectives (e.g. putting more emphasis on mitigation and adaptation) or resource allocation. Also, user behaviors change both as a direct result of climate change impacts or in response to changes in the above-mentioned factors. A review of the existing literature shows that the steady-state analysis approaches are unable to provide a thorough understanding of the transformation of CIS under climate change due to lack of consideration of (Fiksel, 2006): (i) the dynamic behaviors and interactions between infrastructure networks, institutional agencies, and users; (ii) future uncertainty related to climate change impact scenarios.

\section{Capturing complex adaptive behaviors}

Adopting a complex systems perspective is an important element in the assessment of CIS resilience to climate change impacts (Fiksel, 2006; Ostrom, 2007). In a complex system perspective, the resilience of CIS is an emergent property resulting from complex interactions among physical infrastructure assets and multiple institutional actors. In fact, a complex systems framework was successfully adopted in the past for a better understanding of the dynamic interactions and adaptation of ecological systems to the impacts of climate change (Alley et al., 2003; Parmesan, 2006). The literature related to ecological science has made significant advancements in adopting a Complex Adaptive Systems (CAS) perspective for understanding the dynamic interactions affecting the resilience of ecological systems. Evidence suggests that analogies to ecological systems and adopting a CAS approach may reveal new ways to analyze and provide design and decision guidelines for resilient CIS networks (Mostafavi, Abraham, \& Lee, 2012; Xu, Weissburg, Newell, \& Crittenden, 2012). Recently, the complex adaptive nature of CIS has been recognized and a number of studies have started to model sustainability and resilience of CIS based on the principles of CAS modeling. Several studies (e.g. Amin, 2002; Brown, Beyeler, \& Barton, 2004; Mostafavi, Abraham, DeLaurentis, et al. 2011; Rinaldi, 2004; Thomas, North, Macal, \& Peerenboom, 2003) proposed the use of a CAS framework for integrated modeling, robust analysis, and a better understanding of resilience and interdependencies in CIS. However, despite the growing literature in the areas of resilience, conceptualization of CIS as CAS has been hindered by two major limitations: (i) lack of a theoretical framework for better understanding of resilience in CIS as a CAS; and (ii) lack of a methodological framework for modeling the adaptive behaviors, dynamic attributes and processes, and uncertain perturbations in CIS as a CAS.

To address this gap, this study proposed a system-of-systems framework for abstraction of complex adaptive behaviors and interactions among institutional actors and physical infrastructure (Figure 1). Accordingly, CIS are analyzed as systems-of-systems composed of multiple physical infrastructure systems as well as social systems consisting of government regulation agencies, service providers, and consumers. These systems are open (with a changing environment and a dynamic number of participants), heterogeneous, temporally and geographically decentralized, and functionally, operationally, and managerially interdependent. SoS framework for the assessment of CIS would enable capturing the activities of and interactions among the various institutional actors and physical infrastructure, and thus facilitates examining the transformation of CIS under climate change impacts.

\section{Exploratory analysis under uncertainty}

In addition to considering behaviors, planning and decision-making of CIS for climate change adaptation involves significant uncertainty. Hence, conventional ex-post analysis and optimization approaches are not capable of capturing these complex adaptive behaviors and uncertainty (Mostafavi et al. 2011). Another approach to deal with adaptive behaviors and uncertainty in complex systems is called Exploratory Analysis (Kwakkel \& Pruyt, 2013). Exploratory analysis has been developed in the literature related to robust decision-making. Exploratory analysis uses computational models and simulation experiments to conduct scenario analysis and evaluate the behavior of complex systems under uncertainty (Agusdinata, 2008; Mostafavi, Abraham, \& DeLaurentis, 2013). Exploratory analysis is a model-based method for decision support. It is an approach that utilizes different simulation methods (e.g. system dynamics and agent-based modeling) for decision-making in problems that include deep uncertainty. Traditionally, simulation models have been used for predictive analysis; however, exploratory analysis focuses on more explorative use of models based different future scenarios.

Exploratory analysis has been utilized in different studies (e.g. Hristov, 2015; Lempert, Nakicenovic, Sarewitz, \& Schlesinger, 2004; Mohor, Rodriguez, Tomasella, \& Júnior, 2015) for evaluation of climate change impacts. However, the use exploratory analysis in the context of CIS resilience under climate change impacts is rather limited. In this context, exploratory analysis can provide novel insights regarding how CIS performance will evolve under different scenarios of climate change impacts and adaptation actions. Unlike the existing approaches for assessment of 


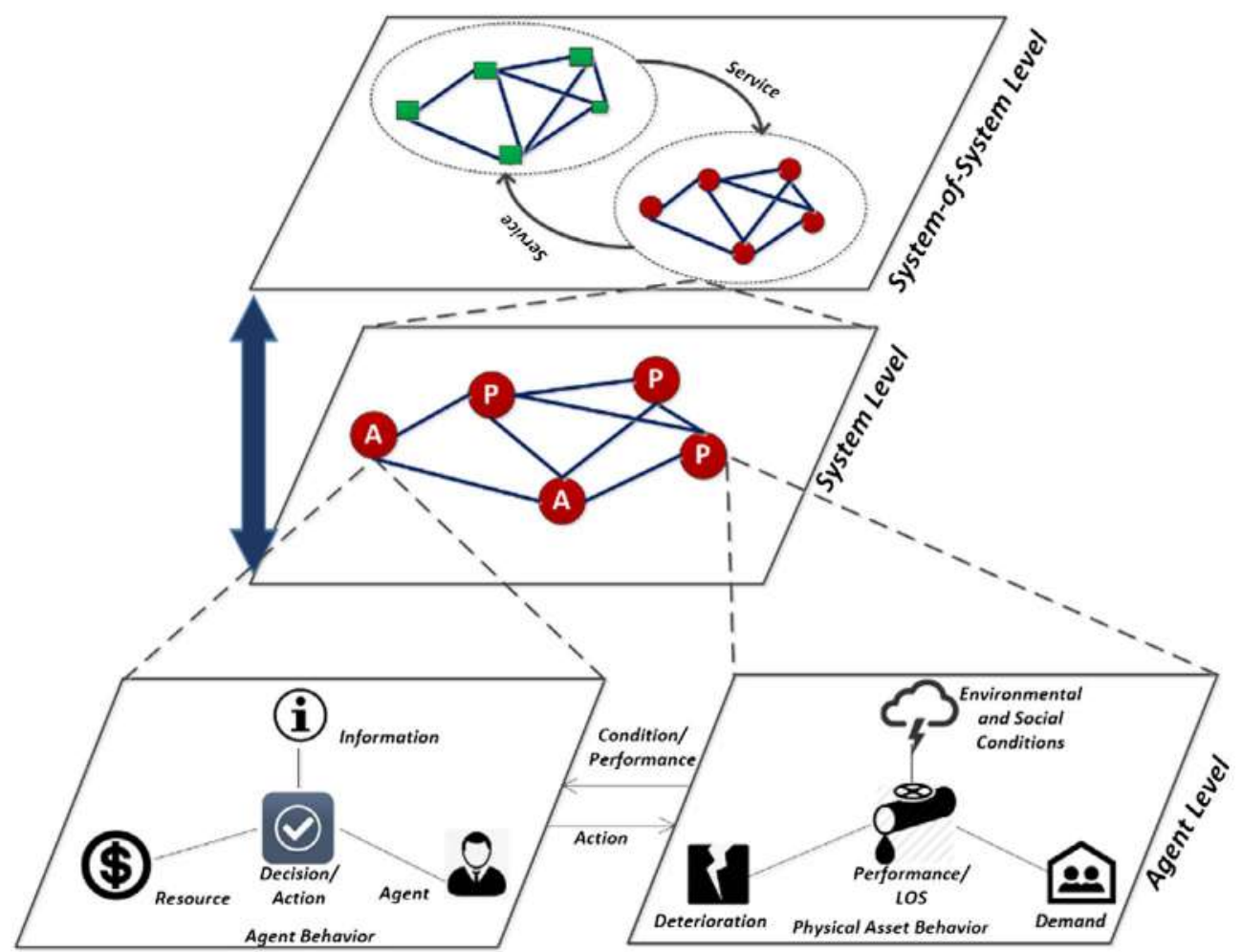

Figure 1. System-of-systems analysis of CIS.

CIS resilience, exploratory analysis does not aim to predict the behavior of a system and does not intend to optimize a system. Instead, exploratory analysis focuses primarily on considering different resilience and adaptation scenarios based on changes in system behavior and future uncertainty. Although the existing literature related to Robust Decision-Making involves frameworks (e.g. Lempert et al., 2004) for assessment of climate change impacts, the existing frameworks are not developed specifically for assessment of infrastructure resilience. Shortridge, Guikema, and Zaitchik (2017) is one of limited studies that adopted a RDM framework for dealing with data scarcity in assessment of infrastructure resilience. The current study complements the current literature related to Robust Decision-Making (RDM) through: (1) establishing a RDM framework in the context of infrastructure resilience; and (2) specifying the important mechanisms and relationships that need to be abstracted and modeled in order to assess infrastructure resilience to climate change impacts.

In the following sections, first, the components of the proposed SoS framework are explained. Then, the application of the proposed framework is explained in an illustrative example pertaining to resilience assessment of a water supply system under sea level rise impacts. In the illustrative example, the proposed SoS framework was used in the creation of a computational model in order to simulate various scenarios and explore adaptation pathways.

\section{System-of-systems framework}

The proposed SoS framework identifies different system elements and attributes that need to be abstracted and modeled in order to enable conducting exploratory analysis on civil infrastructure as CAS. The components of the proposed SoS framework can be implemented through the use of multiple simulation methods. There is no generalized method or model that can capture all the attributes, adaptive behaviors, and dynamic interactions in civil infrastructure. Depending on the objectives of an exploratory analysis, as well as system elements and attributes considered, appropriate simulation models can be adopted and integrated. In presenting different components of the SoS framework, various possible methods for modeling the various systems elements, attributes, and interactions will be discussed.

The proposed SoS framework enables integrating and modeling three principle phenomena (i.e. adaptation decision-making processes of institutional actors, dynamic physical performance of physical infrastructure, and stochastic chronic and acute stressors induced by climate change impacts) that affect the long-term transformation and resilience of civil infrastructure systems. Hence, the proposed framework enables creating integrative computational models composed of multi-method approaches for simulating complex adaptive behaviors in civil infrastructure, and hence conducting exploratory resilience analysis under climate change impacts. 
The proposed SoS framework aims to provide a comprehensive approach for conducting exploratory analysis of civil infrastructure resilience to climate change impacts. The definition phase of the framework determines the specific measures and objectives that need to be taken into consideration for examining climate change impacts and the long-term resilience of infrastructure. The abstraction phase specifies the dynamic mechanisms and complex relationships among climate change stressors, physical networks, and human decision-makers. The implementation phase involves simulation modeling, as well as analysis steps based on robust decision-making techniques in order to identify resilience pathways. Each phase includes a number of tasks which will be described in detail in the following sub-sections.

\section{Definition phase}

The first phase of the analysis is definition. The outcomes of the definition phase will inform the relevant stressors, actor and infrastructure attributes, and metrics to be considered in the abstraction and implementation phases. Definition phase includes two tasks: (i) defining the levels of analysis, the context of analysis, and limitations and (ii) defining the metrics for evaluation of SoS performance and resilience at different levels of analysis. First, the levels of analysis include base, system, and SoS levels. The resilience outcomes at each level are obtained as a result of the interactions between the components at the lower level. For example, the attributes and interactions of institutional actors and physical infrastructure affect the resilience outcomes at the system level. The context of the analysis should define the infrastructure sector as well as the climate change impacts for which the analysis is performed. The context of analysis determines the type of climate change stressors to be included in the analysis, the impact of stressors on physical infrastructure, and the action space of the institutional actors for responding to climate change stressors. For example, assessment of water infrastructure systems under sea level rise impacts would involve different climate change stressors, physical infrastructure impacts, and action space compared to examining road networks performance under the impacts temperature variation. The second task in the definition phase is to define the metrics for evaluation of resilience and performance across different levels. Consideration of different resilience metrics at different levels would depend on the study objective and context. For example, Batouli and Mostafavi (2016b) used a network-level life cycle cost as a metric for evaluation of the impacts of flooding on road infrastructure in order to determine the value of adaptation actions. Other studies (e.g. Dehghani, Flintsch, \& Mcneil, 2014) have used measures of network vulnerability for assessment infrastructure resilience under disruptions caused by natural disasters. Another important consideration is the relationship between different metrics at different levels. Due to the non-linear behaviors in CIS, the resilience metrics at each level cannot simply be determined by aggregating the metrics at the levels below. In other words, resilience performance at the SoS level is an emergent property as a result of the interactions between different systems components at the level below. The aggregation of individual systems resilience may not be an indicator of CIS at the SoS level.

\section{Abstraction phase}

The second phase of the proposed SoS framework is abstraction. In the abstraction phase, relevant institutional actors and physical infrastructure assets and their attributes and interactions at the base-level are captured. There are various attributes and behaviors that affect the internal feedback processes between institutional actors and physical infrastructure assets. For institutional actors, the decision-making behaviors such as information processing, resource allocation, project prioritization, and retrofit/capacity expansion are examples of behaviors that may be abstracted. An important aspect of SoS analysis of CIS resilience is the ability to integrate asset condition degradation, level of service, and vulnerability with the decision-making processes and adaptation actions of institutional actors and enable dynamic analysis over time (Dehghani et al., 2014; Koetse \& Rietveld, 2009; Lambert, Wu, You, Clarens, \& Smith, 2013).

\section{Infrastructure assets}

The dynamic performance of infrastructure assets can be represented using two state variables: (1) Exposure state $\left(\operatorname{Exp}_{i j t}=\right.$ Exposure of asset $i$ to stressor $j$ at time $\left.t\right)$; and (2) Condition state $\left(C_{i t}=\right.$ Condition of asset $i$ at time $\left.t\right)$. Exposure state determines the exposure of an infrastructure asset to climate change stressors. The value of Exposure state variable is between 0 and 1 . For example, if a bridge is exposed to flooding, the Exposure state variable for the bridge is equal to 1. The value of Exposure state variable can be determined based on location of an asset and the hazard exposure models. For example, flood maps can be used for determining the temporal and spatial distribution of flood events. Details about considering stressors in the SoS framework are provided later in this paper.

Another element for representing the behavior of physical infrastructure assets is Condition state variable. Condition state variable determines the physical condition of an asset. For different types of infrastructure, different measures can be used to present their condition states. For example, for road pavements, pavement serviceability 
rating (PSR) index can be used. For bridge superstructure, structural serviceability can be used as the Condition state variable. An important element in determining the Condition state variable is the use of appropriate condition deterioration equations to model the decay rate of physical infrastructure. The condition state variables are determined using this service state variables, which are: (i) the level of service $\left(\operatorname{LOS}_{i t}=\right.$ Level of Servie of asset $i$ at time $\left.t\right)$ of an infrastructure asset based on its condition; and (ii) the fragility $\left(F_{i t}=\operatorname{Prob}\left(\right.\right.$ failure $\left.\mid \operatorname{Exp}_{i j t}\right)=$ Fragility of asset $i$ to stressor exposure $j$ based on its condition at time $t$ ). Determination LOS and Fragility variables based on the Service Limit state variable vary for different types of infrastructure. For example, for water main infrastructure, if pipelines are in good condition, the system will have small amount of water leakage, and thus, the level of service would be high. In the same example, the probability of water main breaks due to a stressor (e.g. earthquake) would be lower if pipes are in good condition. The mathematical representation of service limit state variables for different types of infrastructure assets is limited due to lack of theory. A substitute for mathematical representation would be the use of truth tables to determine the relationships between Condition State variable and Service Limit state variables. In cases where condition-based fragility curves are available, this information can be used to model the fragility of infrastructure. However, when condition-based fragility curves for different types of infrastructure and various hazards are not available, the fragility of infrastructure can be modeled using substitute approaches.

The parameters explained above for representation of dynamic behaviors of infrastructure as assets are affected by the decision-making processes of institutional agencies. For example, building salinity barriers for water wellfields would be an action that reduces the exposure of water infrastructure to saltwater intrusion to aquifers. In addition, the condition of infrastructure assets is improved if the agency implements maintenance and rehabilitation activities. In the following sections, the elements for capturing the adaptive decision-making behaviors of institutional actors are discussed.

\section{Institutional actors}

Given the complexity of civil infrastructure systems, a proper assessment of resilience hinges on an understanding of the decision-making behaviors in social systems exposed to climate change impacts(Chappin \& van der Lei, 2014; Lambert et al., 2013; Patt \& Siebenhüner, 2005). In the context of resilience decision-making, the existing evidence confirms that certain behavioral and social phenomena affect the decision rules related to adaptation actions (Berger \& Troost, 2014; Patt \&
Siebenhüner, 2005). Adaptation refers to anticipation and mitigation of undesirable impacts of climate change on the performance of infrastructure systems. In order to capture the decision-making processes of institutional actors in response to climate change impacts, different decision-theoretic elements can be used. The three main elements of decision-making processes of institutional actors in response to climate change impacts include: (1) identifying exposed infrastructure assets to different stressors under uncertainty; (2) selecting appropriate adaptation actions to reduce exposure or mitigate impacts for the exposed assets given resource constraint; and (3) learning from past decisions and actions, as well as actions of others to improve future decisions. These three elements of adaptation decision-making processes of institutional actors can be captured using different elements of decision theory as explained below:

The first element is related to identifying exposed infrastructure assets to different stressors under uncertainty. This element of decision-making can be captured based on assessing the perception of institutional actors of future climate change impacts. The perception of institutional actors is based on their current available information and may be different from the actual future impacts of stressors. For example, in identifying the exposed infrastructure assets to future flood events, an institutional actor utilizes the available information related to the future flood event exposure to determine what infrastructure assets (e.g. roads and bridges) will be exposed. Since the identification of exposed assets is done based on the information about future stressors and not the actual future stressors, the institutional actors uses the perceived state of nature rather than the actual state of nature to make its decision. If the actual state of nature for stressor $i$ at time $t$ is $S_{t}^{i}$, the perceived state of nature $\left(S_{t}^{\prime}\right)$ would be based on the available information or observation of actual state of nature in the previous period. Accordingly, this element of decision-making processes can be captured using stressors data and conditional decision rules $\left(\operatorname{Exp}_{i j t} \mid S_{t}^{\prime}\right)$. For example, if Bridge $\mathrm{A}$ is located in an area that will be flooded if a fast sea level rise projection occurs, and the institutional actor perceives the occurrence of a fast sea level rise projection in the following period, Bridge A will be identified as exposed by the agency.

Depending on the objectives of an analysis, the actors whose adaptation decision-making processes affect the resilience of the infrastructure of interest should be considered. Hence, the analysis may include multiple actors and their interactions. Modeling various attributes of actors' decision-making processes can be implemented through the use of empirical or theoretical approaches. 
For example, risk attitude of actors can be estimated empirically based on how actors make choices under uncertainty (Dohmen et al., 2011) or theoretically using utility or regret theory. Accordingly, the risk attitude of an actor determines what decision and behavioral rules are used to make choices and take actions under uncertainty.

The impacts of climate change stressors and corresponding adaptation alternatives can be realized at two levels: network and asset levels. For example, coastal flooding is an impact affecting a network of infrastructure for which different adaptation alternatives (e.g. installing storm water pump stations, constructing breakwater barriers, and population relocation) may be considered. At the asset level, the impacts of climate change stressors on different types of infrastructure varies. For example, saltwater intrusion into fresh water wells is one of the major impacts of sea level rise on water supply infrastructure. Possible adaptation action alternatives for coping with saltwater intrusion include exploitation of aquifers in non-affected areas, building desalination capacity in treatment plants, and building additional reclaimed water production facilities. These adaptation actions may be implemented by different actors for the identified exposed assets at different points in time and in response to the perceived state of nature related to different stressors.

The adaptation action space can be defined as $A_{m}^{k}\left(S_{i}^{j}\right)=\left\{A_{1}^{k}, A_{2}^{k}, \ldots \ldots, A_{n}^{k}\right\}$, where $A_{m}^{k}\left(S_{i}^{j}\right)$ is the action $m$ by Actor $k$ in response to perceived state $S_{t}^{\prime}$. The selection of most appropriate action for an exposed asset can be captured based on decision-theoretic approaches such as utility, prospect, and regret minimizing theories depending on the costs and utilities of different adaption actions. The selection of appropriate decision-theoretic approaches depends on the context and objective of the analysis. The available evidence confirms that the decision-making behaviors of institutional actors is not purely rational and hence does not justify the use of conventional decision theory models to explain the actors' decision-making behaviors (Berger \& Troost, 2014; Patt \& Siebenhüner, 2005). Hence, additional behavioral and social phenomena need to be investigated for a better understanding of the decision-making behaviors of institutional actors. For example, an important element that need to be considered is the risk attitude of institutional actors. Since the resilience decision-making processes are made under uncertainty, accounting for the risk attitude of the actors is an important consideration. For example, utility theory can be adopted to examine different risk attitudes $\left(R_{t}=\right.$ Risk Attitude of an Actor at timet $)$ such as risk seeking, risk averse, and risk neutral attitudes. The risk attitude of institutional actors may change based on learning from past decisions. For example, if an actor had selected salinity barrier as the best adaptation action for an exposed wellfield of a water supply system based on a risk neutral attitude, and the selected adaptation action was not effective in mitigating the impacts, the actor's risk attitude may change to risk averse for decision-making in the next decision point.

The third element of decision-making processes of institutional actors is learning. Institutional actors respond to sea level rise impacts based on their learning from the historical impacts and actions of others. In addition, individual actions and risk perception of institutional actors may be in response to the choices and risk perceptions of others (Kasperson \& Kasperson, 1996). As a result, actors respond not to a climate stressor itself, but to the other actors' responses to the stressor (Patt \& Siebenhüner, 2005). Indeed, climate change adaptation is a collection of actors' responses motivated by local concerns. The coordination behaviors of social actors can be captured based on game-theoretic approaches.

In addition to the adaptation decision-making behaviors, the decision-making processes related to regular maintenance and rehabilitation (M\&R) of infrastructure assets should be captured in the SoS framework. The M\&R decision-making processes of institutional actors affect the condition of physical assets. Different elements such as the availability of funding, condition of assets, and prioritization policy of institutional agencies can affect the M\&R decisions. These decision-making elements can be captured using appropriate decision-theoretic approaches as discussed by Batouli et al. (2015) and Batouli and Mostafavi (2016a).

\section{Climate change stressors}

Various scientists have investigated the impacts of climate change from physical, biological, and hazards aspects. However, the translation of the results of climate change impact studies into stressors in the SoS framework require certain considerations. Depending on the context of an analysis, climate change stressors on physical infrastructure can vary from flood and storm surge impacts to saltwater intrusion and bridge scours. In the SoS framework, these impacts can be captured based on their temporal and spatial distribution as well as their magnitude. In order to capture climate change stressors, the results of climate change hazard and impact studies should be translated into data tables of asset exposures $\left(\operatorname{Exp}_{i j t}\right)$ that include information about temporal and spatial distribution for different magnitudes of stressors. An example of such data table is shown in Figure 2.

Another feature of capturing climate change stressors in the SoS framework is the probabilistic occurrence of these stressors. In order to capture the actual state of nature for a stressor at time $t\left(S_{t}^{i}\right)$, the occurrence of the 


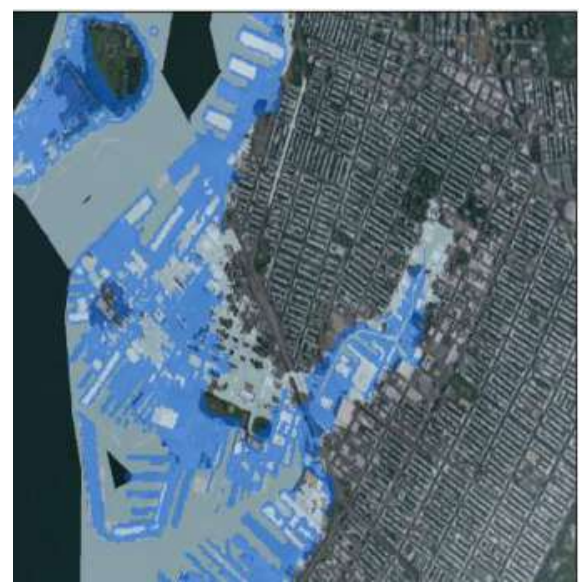

\begin{tabular}{|l|l|l|l|l|}
\hline \multicolumn{2}{|c|}{} & \multicolumn{2}{l|}{$\begin{array}{l}\text { Storm Surge Spatial Distribution } \\
\text { under Different Hurricane } \\
\text { Categories }\end{array}$} \\
\cline { 2 - 5 } & Asset & $\begin{array}{l}\text { Category } \\
\mathbf{3}\end{array}$ & $\begin{array}{l}\text { Category } \\
\mathbf{4}\end{array}$ & $\begin{array}{l}\text { Category } \\
\mathbf{5}\end{array}$ \\
& Bridge A & 0 & 1 & 1 \\
\hline & Bridge B & 0 & 0 & 1 \\
\hline Bridge C & 0 & 1 & 1 \\
\hline Bridge D & 1 & 1 & 1 \\
\hline Bridge E & 0 & 0 & 0 \\
\hline Bridge F & 1 & 1 & 1 \\
\hline
\end{tabular}

Figure 2. Example of abstracting climate change stressors in the SoS framework. *Values in the table represent the exposure of assets (exposure $=1$ means the asset is exposed).

stressor should be examined probabilistically through the use of the existing data and adoption of suitable random process modeling approaches as will be explained in the implementation phase section of the SoS framework.

\section{Infrastructure systems}

The coupled effects of infrastructure assets performance and institutional actors' decision-making processes are used in determining system level performance and resilience. In abstracting system level performance, it is critical to properly abstract the dependencies between different physical assets. Consideration of different types of dependencies between infrastructure assets would depend on the context and objective of the analysis. Rinaldi (2004) identified different types of system dependencies (e.g. physical, logical, and cyber). One or multiple dependencies may be relevant for a specific study.

After the dependencies between infrastructure systems are captured, different system-level performance measures can be investigated. For example, vulnerability is a widely used measure for assessment of system level performance. Vulnerability is defined as the susceptibility of infrastructure networks to climate change impacts that can significantly affect the functionality of infrastructure. The vulnerability of infrastructure can be evaluated using a network analysis approach (e.g. Arianos, Bompard, Carbone, \& Xue, 2009; Christodoulou \& Fragiadakis, 2015; Jenelius, Petersen, \& Mattsson, 2006; Winkler, DueñasOsorio, Stein, \& Subramanian, 2010). In a network analysis approach, each asset in a system is considered as a node and the dependencies between different infrastructure assets is captured based on links between the nodes. Accordingly, disruptions in infrastructure assets can be captured based on the removal of links between the nodes in the network. Then, through the use of graph-theoretic measures (e.g. connectivity and efficiency), the vulnerability of infrastructure networks can be determined.
Another system level measure that can be assessed is system reliability. System reliability can simply be defined as the level of service produced to supply the demand. The level of service supplied can be captured based on the capacity of infrastructure assets in the system. Furthermore, various other system level performance measures can be considered. For example, Batouli et al. (2015) and Batouli and Mostafavi (2016b) used a system level life cycle cost and Batouli and Mostafavi considered a system level life cycle impact measure in the evaluation of system performance. The required measures should be defined at the definition phase of the SoS since the measures influence the abstraction of various infrastructure attributes and dependencies that need to be captured.

\section{Implementation phase}

The third phase of the SoS framework is implementation in which computational representation of abstracted system components are created for conducting simulation experiments and exploratory analysis. An important step in the implementation phase is the selection of appropriate modeling and simulation methods. The selected modeling techniques should be consistent with the characteristics of the system. In the assessment of the impacts of climate change on infrastructure systems, an appropriate modeling technique should capture the dynamic, stochastic, and adaptive nature of system attributes. To this end, different modeling methods can be used for different system components and integrated into a multi-method model.

\section{Modeling methods}

For modeling the performance of infrastructure assets, system dynamics, Markov chain, and mathematical modeling are examples of modeling techniques that can be used. For example, Rehan, Knight, Haas, and Unger 
(2011) and Rashedi and Hegazy (2015) utilized system dynamics for modeling the performance of water distribution infrastructure assets. Ortiz-García, Costello, and Snaith (2006) used dynamic mathematical approaches to model the condition and deterioration of road pavements. For implementing the decision-making and behaviors of institutional actors, agent-based modeling $(\mathrm{ABM})$ can be adopted. ABM is an effective simulation approach for analyzing decision-making processes of actors in infrastructure systems (Bhamidipati, van der Lei, \& Herder, 2015; Mostafavi et al., 2013; Mostafavi et al., 2015; Sanford Bernhardt \& McNeil, 2008). The use of ABM enables: (1) discovering what decision rules, micro-behaviors, and preferences affecting adaptation decisions; and (2) juxtaposing the preferences of various decision makers with the range of adaptation alternatives to determine the distribution of expected outcomes. Finally, climate change stressors can be implemented through the use of appropriate mathematical elements and models. For example, the rate of saltwater intrusion into ground water can be represented using a mathematical function in SoS model. Stochastic climate change stressors, such as flooding and storm surge events, can be implemented using stochastic models such as random processes. For example, the occurrence of storm surge can be modeled using a Poisson Process model with appropriate parameter values. The selection of appropriate modeling approach for implementation of each component is affected by the ability to an integrated the modeling techniques into a multi-method simulation platform. A robust multi-method simulation platform should be able to cope with the complexity of calculating dynamic variables and uncertainties from different sources at different levels of multiple subsystems and modeling methods.

\section{Exploratory analysis}

The ability to conduct exploratory analysis is the most important advantage of the proposed SoS framework. In SoS analysis of infrastructure systems resilience, the results of simulation models should be processed to generate different possibilities and to identify the decision factors affecting resilience. To this end, exploratory analysis of infrastructure resilience explores the outputs of different scenarios by conducting hundreds or thousands of computational experiments that help to analyze the system behavior. The process of exploratory analysis includes different steps (Figure 3). The data obtained from simulated data can be analyzed through various statistical approaches to conduct meta-modeling. To this end, meta-modeling of simulated data can provide insights about the significance of various elements affecting the resilience of infrastructure under climate change impacts. Meta-modeling enables identifying robust pathways across multiple scenarios, assumptions that lead to a certain output, and key trade-offs across pathways. The steps of exploratory analysis will be explained in the next section in the context of an illustrative example.

\section{Illustrative example}

In order to demonstrate the application of the proposed framework, an illustrative example was used to assess the impacts of sea level rise on water supply infrastructure. In this illustrative example, the water supply system is composed of one treatment plant and three groundwater well fields. Sea level rise causes saltwater intrusion in groundwater wells, and thus affect the long-term performance and resilience of the system. Through the use of the proposed SoS framework, different components of the water supply system were abstracted and modeled in order to assess the resilience of the system. The illustrative example captures the water infrastructure characteristics and sea level rise stressors that exist in coastal areas such as the Southeast Florida region. In fact, the sea level rise scenarios and saltwater intrusion rates used in the illustrative example were obtained from Dausman and Langevin (2005) and Southeast Florida Regional Climate Compact (SFRCC) (2011) for Southeast Florida. However, due to the unavailability of all the required data related to Southeast Florida's water supply infrastructure at the time of conducting this study, the demonstration of application of the proposed SoS framework is presented as an illustrative example. Nevertheless, the stressors and attributes considered in the analysis are consistent with the characteristics of real world systems. A dynamic (time-dependent) multi-agent simulation model was created to capture the attributes and interaction among sea level rise stressors (i.e. saltwater intrusion), water supply system, and human decision-maker. The agent classes and their attributes and

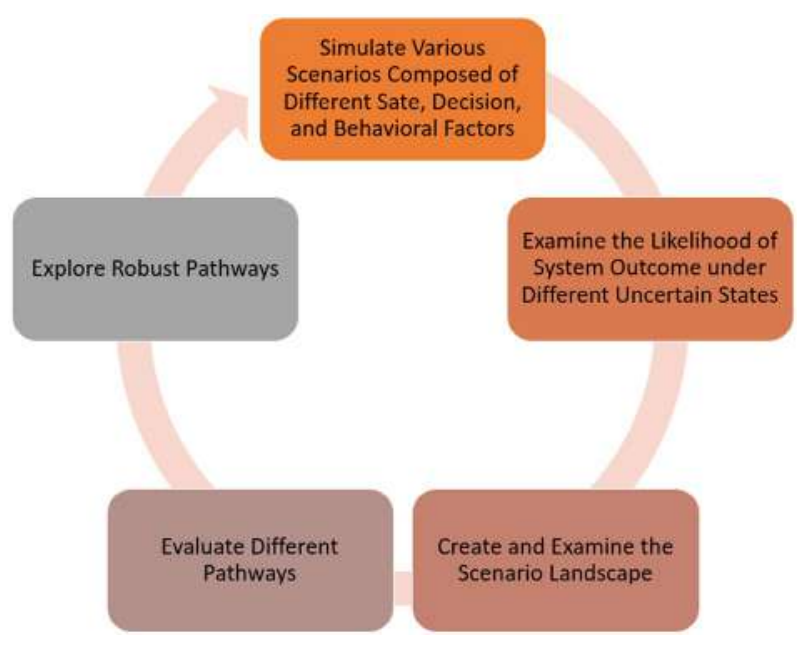

Figure 3. Exploratory analysis steps. 
functions are shown in the Unified Modeling Language (UML) diagram in Figure 4.

\section{Sea level rise stressors}

Sea level rise stressors considered in the illustrative example were twofold: (1) chronic saltwater intrusion due to sea level rise; and (2) acute saltwater intrusion due to storm surge events. A key consideration is accounting for the uncertainty of future sea level rise projections. Despite several studies, there is no consensus among scientists regarding the rate and projections of future sea level rise. Based on a study conducted by the International Panel of Climate Change (IPCC), three sea level rise scenarios are likely: slow ( $1.6 \mathrm{ft})$, moderate $(3.3 \mathrm{ft})$, and fast $(4.9 \mathrm{ft})$ by 2100. Hence, in the illustrative case, the state of nature variable for future sea level rise projections is represented using Equation (1):

$$
S=\left\{S_{\text {slow }}, S_{\text {Moderate }}, S_{\text {Fast }}\right\}
$$

Based on the state of nature, the rate of saltwater intrusion into groundwater wells can be determined based on the findings of groundwater models. For example, in the illustrative example, the results of the groundwater modeling conducted in Southeast Florida was used to determine the rate of saltwater intrusion into the well fields: (1) 0.35 inch/year for slow sea level rise scenario; (2) $0.42 \mathrm{inch} /$ year for moderate scenario; and (3) $0.68 \mathrm{inch} /$ year for the fast scenario. The rate of saltwater intrusion was used to determine the year in which each well field gets exposed under different sea level rise scenarios.

The second stressor on the water supply system of the illustrative example is acute saltwater intrusion caused by storm surge. Hurricane and storm events can cause storm surges that lead to wash-over saltwater intrusion into the well fields. The exposure of well fields to saltwater intrusion depends on the occurrence of storm surges and its magnitude. The magnitude of storm surge events varies based on the state of future sea level rise. In the illustrative example, the occurrence of storm surge events was modeled through the use of a Poisson process model as shown in Equation (2):

$$
\operatorname{Pr}(\text { Storm Surge } \mid \text { Sea Level Rise State })=\lambda \times e^{\lambda}
$$

where $\lambda$ is the likelihood of having one storm surge event at each year. In the illustrative example $\lambda$ values of $3,3.5$, and $4 \%$ were assumed for slow, moderate, and fast seal level rise scenarios, respectively. Accordingly, the threat of each wellfield to saltwater intrusion caused by storm surge was determined using Equation (3):

$\operatorname{Pr}($ Saltwater intrusion in welli|Storm surge) $=$ Well Exposure Threshold

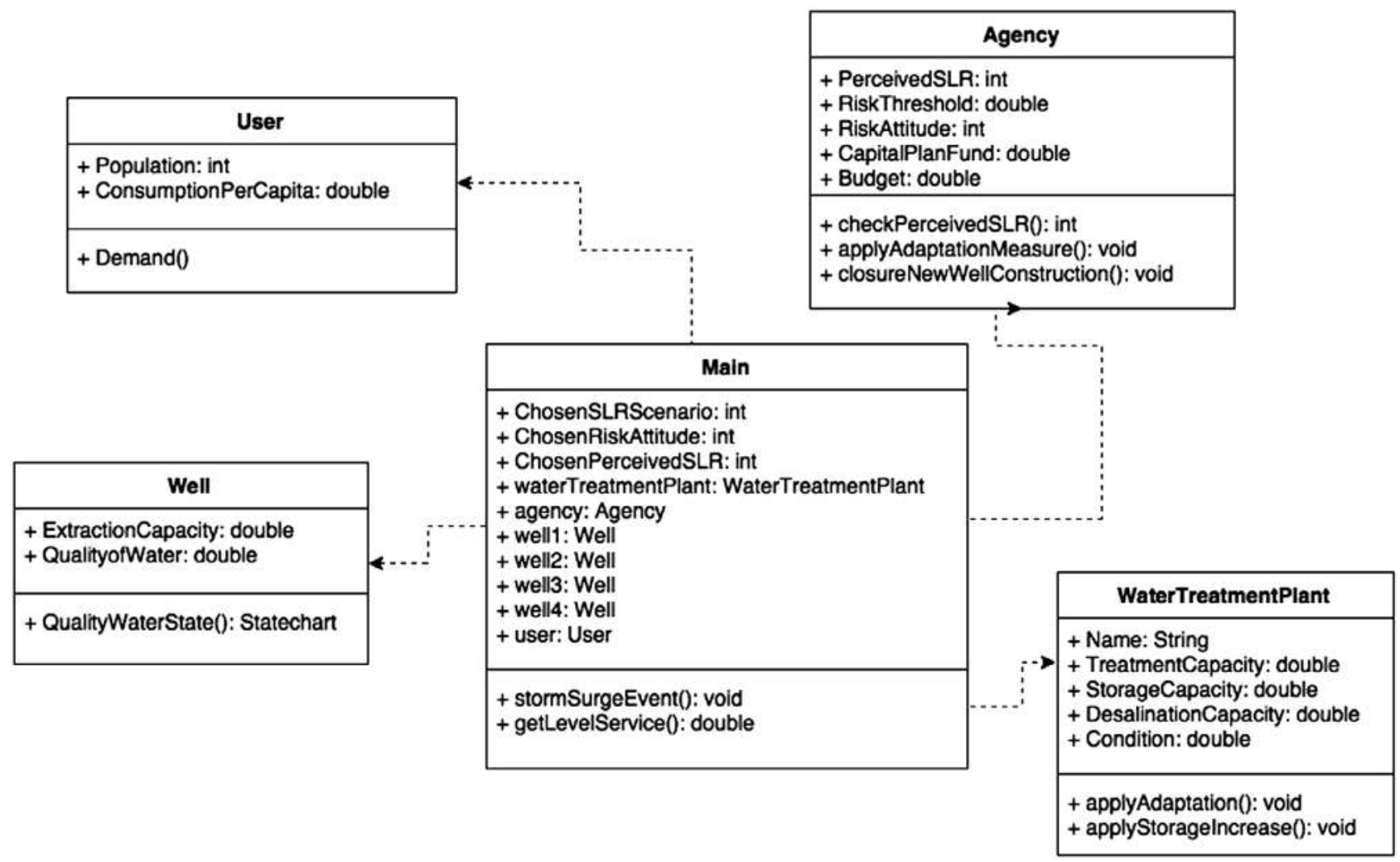

Figure 4. UML class diagram of computational simulation model. 
where, well threat probability is contingent on the location of the well and magnitude of storm surge events. In this illustrative example, well threat threshold values between $30 \%$ and $50 \%$ were assumed for different well fields in the system. a Poisson Process. Accordingly, the actor will evaluate the probability that one storm surge event occurs during the next decision horizon. Based on the perceived scenario of sea level rise and likelihood of storm surge during the next horizon, exposed wells are identified using Equations (6)-(8):

Likelihood of at least one storm surge during the next period $=\lambda \times e^{-\lambda}$

$\operatorname{Exp}_{i t}=1$; If Likelihood of at least one storm surge during the next period $<$ Risk Tolerance

$$
\begin{aligned}
\operatorname{Exp}_{i t}= & 0 ; \text { If Likelihood of at least one storm surge during the next period } \\
& >\text { Risk Tolerance }
\end{aligned}
$$

\section{Institutional actor decision-making}

In the illustrative example, the institutional actor operates and manages the treatment plant and groundwater fields. The decision-making process for adaptation occurs at certain time intervals and certain decision points (every five years in this illustrative example). The adaptation decision-making process includes two steps. The first step of adaptation decision-making is to identify wells that will get exposed during the next decision horizon (e.g. 5 years in the illustrative example). The exposure of the wells is determined based on the perceived scenario of sea level rise and the associated salt water intrusion rate for each scenario. Because of the uncertainty in projecting sea level rise, the perceived sea level rise of the actor may be different from the actual state of nature. Accordingly, the exposure of each well based on the perceived sea level rise scenario is determined using Equations (4) and (5):

$$
\begin{aligned}
\operatorname{Exp}_{i t}= & 1 ; \text { If Well Distance from Salinity Line } \\
& <(\text { Rate of Saltwater Intrusion } \\
& \times \text { Decision Horizon Duration }) \\
\operatorname{Exp}_{i t}= & 0 ; \text { If Well Distance from Salinity Line } \\
& >(\text { Rate of Saltwater Intrusion } \\
& \times \text { Decision Horizon Duration })
\end{aligned}
$$

where, $\operatorname{Exp}_{i t}$ is the exposure of well $i$ during decision period $t$, and decision horizon duration is the number of years during which the exposure of wells are analyzed (i.e. 5 years in the illustrative example). The rate of saltwater instruction is obtained based on the perceived sea level rise scenario at decision point $t$.

Another element affecting the exposure of well fields is the occurrence of storm surge. As mentioned earlier, the occurrence of storm surge is modeled through the use of where, $\lambda$ is the probability of storm surge related to a sea level rise scenario, $\operatorname{Exp}_{i t}$ is the exposure of well $i$ during decision period $t$, risk tolerance is the acceptable level of risk by the actor. The risk tolerance threshold values vary based on the risk attitude of the actor. In the illustrative example, the following values were used: $10 \%$ for risk averse, $20 \%$ for risk neutral, and 30\% for risk seeking.

Based on the consideration of wells exposure to sea level rise and storm surge, if no wells are identified to get exposed to saltwater intrusion, the agency does not implement any adaptation actions and proceeds to the next decision point. If one or more wells are identified to potentially get exposed to saltwater intrusion, the next step of adaptation decision-making is to select appropriate adaptation actions. In the illustrative example, the adaptation action space considered the following adaptation actions: (1) adding desalination capacity to the treatment plant; (2) building salinity barriers to protect the well fields; (3) implement deep well injection to control ground water levels; (4) adding storage capacity; and (5) closing a wellfield and exploiting new well fields farther from the saltwater line. Each adaptation action has different cost and effect on the water supply system. Adding desalination capacity will increase the ability of the system to desalinate sea water. Building salinity barriers and deep well injection reduce the rate of saltwater intrusion into groundwater wells. Adding storage capacity increases the redundancy of the system during service disruptions caused by storm surge events. Table 1 summarize the cost

Table 1. Cost of adaptation actions in the illustrative case.

\begin{tabular}{lc}
\hline Adaptation action & Cost (\$ Million) \\
\hline Desalination facility & 550 \\
Salinity barrier & 250 \\
Deep well injection & 200 \\
Addition of storage & 120 \\
Abandoning old wells and new well construction & 350 \\
\hline
\end{tabular}


information for each adaptation action. The effectiveness of each adaptation action was determined based its influence on the performance of water supply (explained later in this section).

In selection of adaptation actions, the risk attitude of the institutional actors affects what decision-theoretic rules are used. If the actor has a risk-averse attitude, the actions are selected in order to minimize the impacts of saltwater intrusion. If the actor has risk-seeking attitude, the actions are taken in order to minimize costs. If the actor has a risk neutral attitude, decision-making process includes a benefit-cost analysis (i.e. an action with above average adaptation effectiveness and costs). Based on the available adaptation funding, risk attitude of the actor, and corresponding decision rules, adaptation actions are selected for each exposed well.

Prior to the next decision point, the actor evaluates the decisions and actions in the previous decision point and adapts the perceived sea level rise and risk attitude. If the actor did not identify the exposure of wells properly, the perceived sea level rise scenario is updated. For example, if the actor identified that a well has experienced saltwater intrusion while it was not identified as exposed in the previous step, the actor updates the perceived sea level rise state accordingly (e.g. from slow to moderate or from moderate to fast). Similarly, if the actor selected an adaptation action that was not effective in mitigating saltwater intrusion, the risk attitude of the actor is updated (e.g. from risk neutral to risk averse). Through this process, the adaptive decision-making behaviors of the institutional actor were captured during a 20-year analysis horizon with decision points every five years. In the illustrative case, the risk preferences of the human decision-maker were captured through the use of a simplified method (i.e. threshold values). However, future studies can adopt different decision-theoretic methods (e.g. regret theory and prospect theory) to better capture the risk behaviors of human decision-makers in the proposed SoS framework.

\section{Water system performance}

The water system in this illustrative example is composed of three components: (1) treatment plant, (2) reservoir, and (3) wells. The attributes of each component of the water system is summarized in Table 2.

The performance of water supply system in this illustrative example was evaluated based on the level of service, which is the amount of water that the system can supply, using Equation (9):
Table 2. Attributes of water systems in the illustrative case.

\begin{tabular}{ll}
\hline System component & \multicolumn{1}{c}{ Attributes } \\
\hline Treatment plant & Desalination capacity \\
Reservoir & Storage capacity \\
Wells & Extraction rate; water quality \\
\hline
\end{tabular}

$$
\begin{aligned}
& \text { Maximum Annual Water Supply } \\
& \begin{aligned}
= & \left.\operatorname{Min}\left(\sum \text { (Extraction from wells }\right), \text { Desalination Capacity }\right) \\
& \times \text { Intrustion Indicator }+(1-\text { Intrusion Indicator }) \\
& \left.\times\left(\sum \text { (Extraction from wells }\right)+\text { Storage Capacity }\right)
\end{aligned}
\end{aligned}
$$

Without any storage capacity, the annual water supply of the system is equal to the amount of water extracted and treated from wells. Desalination capacity enables the treatment plant to perform desalination in case a well experiences saltwater intrusion. In the case of no saltwater intrusion, desalination capacity is not utilized. Storage capacity is used in cases of storm surge saltwater intrusion. Saltwater intrusions caused by storm surge are temporary. When saltwater intrusion occurs, if desalination capacity is zero, the amount of extraction would be zero. If desalination capacity exists, the amount of extraction would be equal to the desalination capacity. If a well is disrupted due to storm surge (due to over-wash intrusion), the storage capacity can be utilized as a backup. Storage capacity is only used during saltwater intrusion caused by storm-surge. In Equation (9), intrusion indicator is a binary variable (it is zero, if there is no saltwater intrusion; it is 1 , otherwise). At the beginning of the simulation, the system does not have any storage or desalination capacity. These capacities are added to the system based on the adaptation actions of the actor.

The resilience of the water supply system is determined based on a measure called Service Reliability Index (SRI), which captures the reliability of water supply to meet the demand. SRI is calculated using Equation (10):

$$
\text { Service relaibility Index }=\frac{\sum_{t=1}^{n} \text { Annual Water Supply }}{\sum_{t=1}^{n} \text { Annual Demand }}
$$

If SRI is less than 1, it shows a disruption in a system. If SRI is greater than one, it shows a redundancy in the system. 


\section{Model verification}

Since the illustrative example was based on a hypothetical system, validation of results was not relevant. Nevertheless, internal verification of the simulation model was conducted to ensure the completeness, correctness, consistency, and coherence of the computational simulation models. In addition, the components of the model and their relationships were evaluated by three subject matter experts (SMEs) involved in planning and adaptation of water systems in order to conduct a face verification. The SMEs included engineers and managers of the Miami-Dade's Water and Sewer Department (WASD) as well as the engineers and planners in the City of Miami Beach. All the SMEs had more than five years of experience in planning activities related to water infrastructure and resilience. Through the process of face verification, the SMEs evaluated whether the model captures significant system components, attributes, and relationships. Due to the illustrative nature of the case study, no further verification and validation were conducted.

\section{Computational simulation and exploratory analysis}

The model developed for the illustrative example includes an animation component which helps in visualizing the effects of different inputs on the performance of the water system under different scenarios of sea level rise. The inputs for each scenario include the actual sea level rise scenario, the perceived sea level rise scenario, and actor's risk attitude at the beginning of the simulation, and the funding available for adaptation actions at each decision point.

In addition to evaluation of individual scenarios and evaluation of different dynamic behaviors in each scenario, the simulation model can be used for exploratory analysis in order to create the resilience landscape of the system. In fact, the ultimate goal of exploratory analysis is to simulate the adaptation landscape and identify robust adaptation strategies that are effective across various climate change scenarios. Hence, the results of simulation models should be processed to generate the analysis landscape and to identify the decision factors affecting the outcomes. The resilience landscape is a treelike structure composed of various scenarios of climate change stressors and adaptation actions. Each scenario leads to a resilience performance outcome (e.g. service reliability). Exploratory analysis includes the following steps:

\section{Simulate various scenarios}

First, meta-modeling was used for exploring the variation of output variables as functions of different input variables in the simulation model. Meta-modeling is the use of data obtained from several simulation experiments in statistical methods in order to better understand the relationships between the input variables and the output variables. Through scenario analysis, 1000 scenarios composed of different combinations of input factors (e.g. actual sea level rise, initial budget, adaptation funding, and actor's risk attitude) were implemented.

\section{Examine different likelihoods of uncertain scenarios}

Figure 5 shows the simulation results related to the probability distributions of Service Reliability Index (SRI) values under different actual sea level rise scenarios. As shown in Figure 5, the probability of achieving greater SRI in the system varies in different sea level rise scenarios. Under slow sea level rise scenario, the likelihood of achieving SRI values of greater than $95 \%$ is about $70 \%$. There is only $10 \%$ likelihood that under slow sea level rise the SRI of the system will be less than $90 \%$. These likelihoods are different in moderate and fast sea level rise scenarios. Under moderate sea level rise, there is about $50 \%$ likelihood that the system SRI is less than $90 \%$ and the likelihood of having very high SRI values (i.e. greater than $95 \%$ ) is about $30 \%$. This likelihood is even smaller under fast sea level rise scenario, in which there is less than $12 \%$ likelihood that the system SRI is greater than $90 \%$.

\section{Create and examine the scenario landscape}

The next step of the exploratory analysis is to identify scenarios leading to different system SRI values. Different data mining methodologies, such as regression, clustering, classification model, and neural networks, could be used for creation of the meta-model. Regression and neural network models are useful for developing meta-models to be used for prediction purposes. Clustering and classification models are beneficial for creation of meta-models to be used for explaining the attributes pertaining to certain outputs. Tree-based statistical approaches, such as Classification and Regression Tree (CART), can be used both for explaining the impact of different system attributes as well as generating various scenarios and pathways. CART is a nonparametric technique that can select, from among a large number of variables, the most important variables in determining the outcome variable to be explained and their interactions (Breiman, Friedman, Stone, \& Olshen, 1984). A regression tree is a tree-structured representation in which a regression model is fitted to the data in each partition. An advantage of CART analysis is that it facilitates identification of significant factors affecting the model outputs as well as the scenarios leading to the desired resilience outcomes. In the illustrative example, CART analysis was used for conducting meta-modeling on the data obtained from the simulation model. Other mathematical techniques can also be adopted to account for deep future uncertainty 


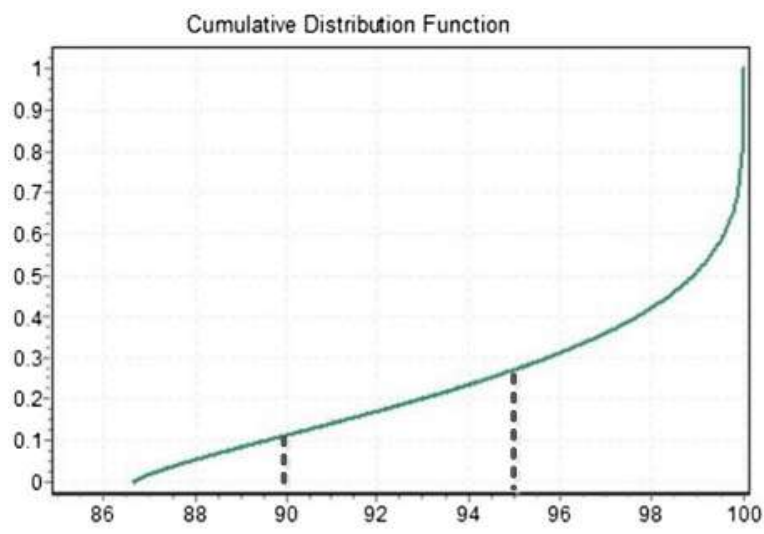

Service Reliability Index - Slow Sea Level Rise Scenario

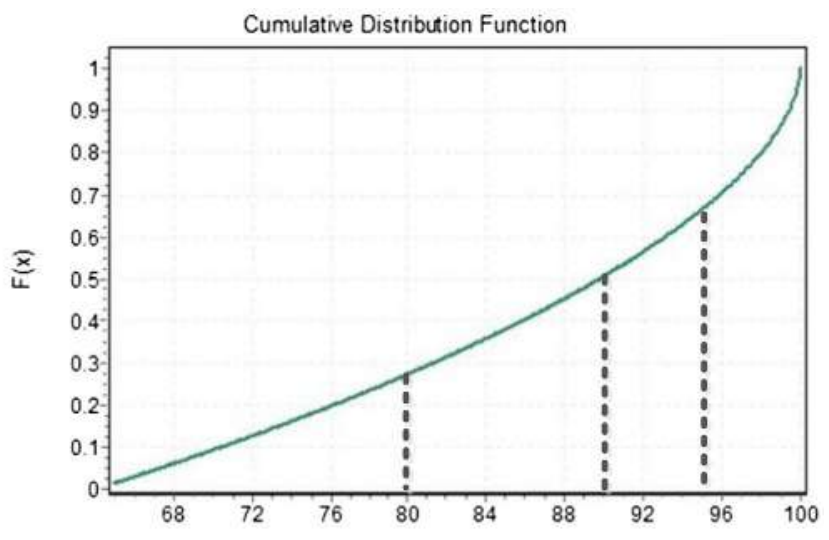

Service Reliability Index - Moderate Sea Level Rise Scenario

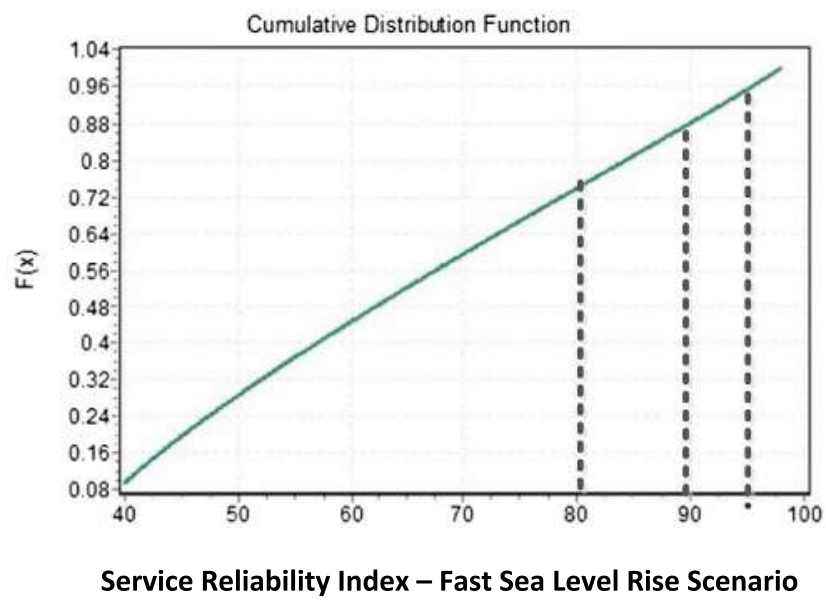

Figure 5. System SRI probability distributions under different sea level rise scenarios.

while conducting exploratory analysis using the proposed framework.

In this illustrative example, the simulated data were used for meta-modeling using CART analysis. The simulated scenario landscape was investigated (based on the best fit CART model determined by the r-square value) to explore the scenarios which could lead to a greater reliability in the water system. In a scenario landscape, each path (consisting of a number of branches) leads to a terminal node. Each path represents an adaptation scenario, and each terminal node represents an outcome. Each branch of a scenario represents specific values of model parameters. Model parameters that are located in higher branches of the landscape are of more significance in affecting the outcome. Further details about CART analysis can be found at Hastie, Tibshirani, and Friedman (2008).

Figure 6 shows CART diagram that shows different scenarios leading to different SRI values. The CART diagram provides two insights. First, the factors located in the higher branch of the diagram have more significant effects on the system outcome. In this illustrative example, the most significant factor affecting the system outcome is the actual sea level rise scenario. This implies that, regardless of the actor's and infrastructure system attributes, the future performance of the system is sensitive to the actual sea level rise scenario.

The second insight obtained from the CART diagram is identification scenarios that lead to desired outcomes under each actual sea level rise scenario. To this end, the SRI values were divided and color-coded into four categories: (1) Very high (SRI > 95\% - color-coded with green); (2) High ( $95 \%>$ SRI > 90\% - color-coded with blue); (3) Moderate $(90 \%>$ SRI $>80 \%$ - color-coded with yellow); and (4) Low ( $80 \%>$ SRI $>90 \%$ - color-coded with red). Accordingly, different scenarios were examined to identify pathways towards greater system performance under each sea level rise scenario. Under slow sea level rise scenario and with a risk-seeking attitude in decision-making, high values of SRI can be obtained if the adaptation funding at each decision step is greater than $\$ 400 \mathrm{M}$; otherwise, with adaptation funding less than $\$ 400 \mathrm{M}$ the SRI values will be in the high category range. If risk attitude is risk averse or risk neutral under slow sea level rise scenario, a lower adaptation funding can lead to higher SRI values. 


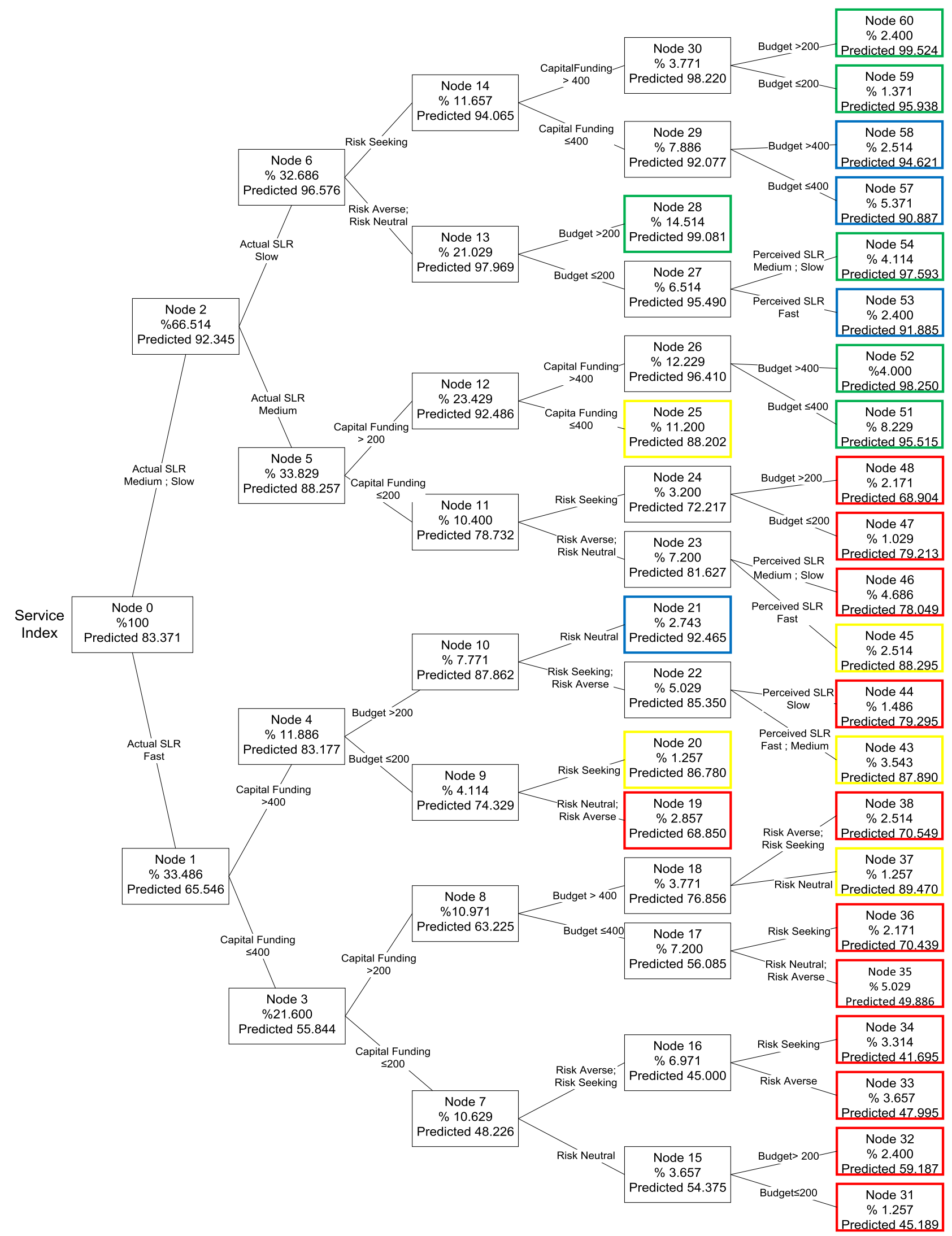

Figure 6. Scenario analysis using Classification and Regression Tree (CART) analysis.

Under this scenario, if adaptation funding is greater than \$200 M, SRI values will be very high. Under this scenario, very high SRI values can be obtained with a funding of less than $\$ 200 \mathrm{M}$ as long as the actor has a correct perception about sea level rise (i.e. perceived sea level rise is also slow). If the actor has an incorrect perception about sea 
level rise scenario, SRI values will be in the high category. This result has an interesting implication: if the adaptation funding is not sufficient, over-estimation of SLR could lead to sub-optimal adaptation planning which would lead to lower SRI values.

Under moderate sea level rise scenario, achieving very high SRI values would not be possible regardless of the risk attitude and adaptation funding levels. Under moderate sea level rise scenario, if adaptation funding is greater than $\$ 400 \mathrm{M}$, the SRI values will be in the high category. If adaptation funding is between $\$ 200$ and $\$ 400 \mathrm{M}$, the SRI values will be in the low category if the agency underestimates the sea level rise scenario (i.e. perceived sea level rise is slow while actual sea level rise is moderate). Under the same funding range, if the agency has correct perception about the sea level rise scenario, SRI values will be in the moderate category. Under the fast sea level rise scenario, high SRI values can only be obtained if the adaptation funding level is greater than $\$ 400 \mathrm{M}$. If adaptation funding is between $\$ 200$ and $\$ 400 \mathrm{M}$, the SRI values will be in the low category in most of the scenario. Only if the agency has a correct perception and the risk attitude is neutral, moderate SRI values can be obtained with adaptation funding ranging between $\$ 200$ and $\$ 400 \mathrm{M}$.

\section{Evaluate different pathways}

This exploration of scenarios helped in identification of different pathways toward a greater performance in the system as shown in Table 3. Each pathway is composed of uncertain scenario (i.e. sea level rise scenario) as well as decision and behavioral factors leading to a certain system outcome (i.e. SRI). In decision-making under uncertainty, the objective is to identify robust decisions that can lead to the desired outcomes under different uncertain scenarios. The desired outcome in this illustrative example was to have high SRI values.

\section{Explore robust pathways}

Through the investigation of different pathways, five pathways $(1,2,3,4$, and 7$)$ were identified that lead to very high or high SRI values. Three of these five pathways are related to the slow sea level rise scenario. Only one pathway lead to high SRI values under moderate sea level rise scenario and one for fast sea level rise scenario. A common attribute of these pathways is an adaptation funding level of greater than $\$ 400 \mathrm{M}$ at each decision point. Hence, for this illustrative example, a robust pathway for adaptation to future uncertain sea level rise scenario will include an adaptation funding of greater than $\$ 400 \mathrm{M}$. While this level of funding would lead to high SRI values, with any risk attitude, under slow and moderate sea level rise, it requires a risk neutral attitude in decision-making under fast sea level rise scenario. This implies that, under the uncertainty of future sea level rise scenarios, having a risk neutral and risk averse attitudes would enable achieving high SRI values under all sea level rise possibilities.

\section{Discussion and concluding remarks}

The main contribution of this work is the establishment of a framework in order to capture complex adaptive mechanisms affecting the resilience of infrastructure systems under climate change impacts. While the existing literature highlights the importance of a complex adaptive perspective in analysis of infrastructure systems, a framework for implementing such analysis was missing. In particular, the proposed framework enables capturing the interactions among three important mechanisms simultaneously: (1) external stressors induced by climate change; (2) the adaptation decision-making processes of the actors; and (3) the characteristics of physical infrastructure. Examination of these mechanisms and their relationship is particularly important in the context of resilience assessments to climate change impacts. However, the existing resilience frameworks and models (e.g. Guidotti et al., 2016; Ouyang, Dueñas-Osorio, \& Min, 2012; Reed, Kapur, \& Christie, 2009) primarily focus on the characteristics of physical infrastructure networks and assess resilience to acute stressors and disruptions. Unlike acute stressors (such as natural disasters), the stressors induced by climate change are chronic in nature and affect infrastructure through different mechanisms (e.g. physical degradation or changes in actors' decision-making behaviors). The proposed framework enables abstraction and

Table 3. Scenario pathways in the illustrative case.

\begin{tabular}{|c|c|c|c|c|c|}
\hline Pathway \# & SLR scenario & Information uncertainty & Risk attitude & Adaptation funding & SRI category \\
\hline 1 & Slow & Yes & Any & $>\$ 400 \mathrm{M}$ & Very high \\
\hline 2 & Slow & No & Any & $\$ 400 M>>\$ 200 M$ & Very high \\
\hline 3 & Slow & Yes & Risk neutral or risk averse & $<\$ 400 \mathrm{M}$ & High \\
\hline 4 & Moderate & Yes & Any & $>\$ 400 \mathrm{M}$ & High \\
\hline 5 & Moderate & Yes & Risk neutral or risk averse & $\$ 400 M>>\$ 200 M$ & Moderate \\
\hline 6 & Moderate & Yes & Any & $\$ 400 M>>\$ 200 M$ & Low \\
\hline 7 & Fast & Yes & Risk neutral & $>\$ 400 \mathrm{M}$ & High \\
\hline 8 & Fast & No & Any & $\$ 400 M>>\$ 200 M$ & Moderate \\
\hline 9 & Fast & Yes & Any & $\$ 400 M>>\$ 200 M$ & Low \\
\hline
\end{tabular}


modeling of these mechanisms and interactions simultaneously in order to conduct exploratory analysis of longterm outcomes.

The SoS framework enables integration of various decision-theoretic, stochastic, and physical infrastructure models needed to simulate the long-term evolution and uncertainty in CIS for resilience analysis to climate change impacts. Integration of various models into an integrated framework provides opportunities for exploring new dimensions of resilience.

Finally, the implementation of the SoS framework enables conducting exploratory analysis in order to make robust decisions under uncertainty. Exploratory analysis and modeling has emerged recently in order to provide an approach for robust decision-making under uncertainty. Unlike conventional modeling approaches that are intended for prediction and optimization purposes, exploratory analysis aims to capture adaptive behaviors and dynamic interactions in complex systems and uncertainty and examine the probability of various possibilities. Through exploratory analysis, various scenario landscapes are simulated and evaluated in order to identify robust pathways that lead to the desired outcomes in a system. While exploratory analysis has been successfully adopted in assessment of climate change uncertainty in other contexts, its use in the context of CIS has been very limited due to the lack of appropriate theoretical and methodological frameworks. The SoS framework proposed in this study addresses this gap in order to implement further exploratory analysis studies in the context of CIS. In particular, assessment of CIS resilience to climate change impacts is a domain in which traditional optimization and analytical approaches have failed to provide meaningful insights for robust planning and decision-making. The illustrative example results demonstrated the utilization of the SoS framework for identifying robust adaptation pathways under sea level rise uncertainty. The application of the proposed SoS framework in future studies can advance the use of exploratory analysis in the context of CIS, and thus lead to better understanding of resilience and sustainability, development of more effective solution concepts, and formulation of robust adaptation strategies and policies.

\section{Acknowledgment}

Any opinions, findings, and conclusions or recommendations expressed in this material are those of the author(s) and do not necessarily reflect the views of the National Science Foundation.

\section{Disclosure statement}

No potential conflict of interest was reported by the author.

\section{Funding}

This work was supported by National Science Foundation (NSF) Sustainability Research Network (SRN) Cooperative Agreement [grant number 1444758].

\section{Notes on contributors}

Ali Mostafavi, $\mathrm{PhD}$, is an assistant professor at the Zachry Department of Civil Engineering at Texas A\&M University. He received his $\mathrm{PhD}$ in Civil Engineering at Purdue University in August 2013. Ali Mostafavi directs the Infrastructure Systemof-Systems (I-SoS) Lab. His team investigates resilience and network dynamics at the interface of human and engineered systems and system-of-system by creating novel computational modeling.

\section{References}

Agusdinata, B. (2008). Exploratory modeling and analysis: A promising method to deal with deep uncertainty. TU Delft: Delft University of Technology.

Alley, R. B., Marotzke, J., Nordhaus, W. D., Overpeck, J. T., Peteet, D. M., Pielke, R. A., ... Wallace, J. M. (2003). Abrupt climate change. Science, 299(5615), 2005-2010.

Amin, M. (2002). Toward Secure and resilient interdependent infrastructures. Journal of Infrastructure System, 8(3), 67-75.

Arianos, S., Bompard, E., Carbone, A., \& Xue, F. (2009). Power grid vulnerability: A complex network approach. Chaos, 19(1), 013119. doi:10.1063/1.3077229

Batouli, M., \& Mostafavi, A. (2016a). A simulation framework for sustainability assessment in evolving socio-technical infrastructure systems. Procedia Engineering, 145, 34-41.

Batouli, M., \& Mostafavi, A. (2016b). Assessment of sea-level rise adaptations in coastal infrastructure systems: Robust decision making under uncertainty. In Construction research congress 2016 (pp. 1455-1464).

Batouli, M., Swei, O. A., Zhu, J., Gregory, J., Kirchain, R., \& Mostafavi, A. (2015, June). A simulation framework for network level cost analysis in infrastructure systems. In In international workshop on computing in civil engineering. Austin, TX: American Society of Civil Engineers.

Berger, T., \& Troost, C. (2014). Agent-based Modelling of climate adaptation and mitigation options in agriculture. Journal of Agricultural Economics, 65(2), 323-348. doi:10.1111/1477-9552.12045

Bhamidipati, S., van der Lei, T., \& Herder, P. (2015). From mitigation to adaptation in asset management for climate change: A discussion. In Proceedings of the 7th World Congress on Engineering Asset Management (WCEAM 2012) (pp. 103-115). Springer International Publishing.

Breiman, L., Friedman, J., Stone, C. J., \& Olshen, R. A. (1984). Classification and regression trees. Belmont: CRC Press.

Brown, T., Beyeler, W., \& Barton, D. (2004). Assessing infrastructure interdependencies: The challenge of risk analysis for complex adaptive systems. International Journal of Critical Infrastructure, 1(1), 108-117.

Chappin, E. J. L., \& van der Lei, T. (2014). Adaptation of interconnected infrastructures to climate change: A sociotechnical systems perspective. Utilities Policy, 31, 10-17. doi:10.1016/j.jup.2014.07.003 
Christodoulou, S. E., \& Fragiadakis, M. (2015). Vulnerability assessment of water distribution system considering performance data. Journal of Infrastructure Systems, 21(2), 04014040. doi:10.1061/(ASCE)IS.1943-555X.0000224

Dausman, A., \& Langevin, C. D. (2005). Movement of the saltwater interface in the surficial aquifer system in response to hydrologic stresses and water-management practices (pp. 2004-5256). Broward County, FL: Scientific Investigations Report. Retrieved from http://pubs.usgs.gov/sir/2004/5256/

Dehghani, M. S., Flintsch, G., Mcneil, S. (2014). Impact of road conditions and disruption uncertainties on network vulnerability. Journal of Infrastructure Systems, 20(3), 04014015. doi:10.1061/(ASCE)IS.1943-555X.0000205

Dohmen, T., Falk, A., Huffman, D., Sunde, U., Schupp, J., \& Wagner, G. G. (2011). Individual risk attitudes: Measurement, determinants, and behavioral consequences. Journal of the European Economic Association, 9(3), 522-550.

Fiksel, J. (2006). Sustainability and resilience: Toward a systems approach. Science, Practice \& Policy, 2(2), 14-21.

Guidotti, R., Chmielewski, H., Unnikrishnan, V., Gardoni, P., McAllister, T., \& van de Lindt, J. (2016). Modeling the resilience of critical infrastructure: The role of network dependencies. Sustainable and Resilient Infrastructure, 1(34), 153-168.

Hastie, T., Tibshirani, R., \& Friedman, J. (2008). The elements of statistical learning. New York, NY: Springer series in statistics.

Heller, M. (2001). Interdependencies in civil infrastructure systems. The Bridge, 31(4), 9-15.

Hristov, J. (2015). An exploratory analysis of the impact of climate change on Macedonian agriculture. In 2015 conference, August 9-14, 2015, Milan, Italy (No. 211747). International Association of Agricultural Economists.

Jenelius, E., Petersen, T., \& Mattsson, L. G. (2006). Importance and exposure in road network vulnerability analysis. Transportation Research Part A: Policy and Practice, 40(7), 537-560. doi:10.1016/j.tra.2005.11.003

Kasperson, R. E., \& Kasperson, J. X. (1996). The social amplification and attenuation of risk. The ANNALS of the American Academy of Political and Social Science, 545(1), 95-105. doi:10.1177/0002716296545001010

Koetse, M. J., \& Rietveld, P. (2009). The impact of climate change and weather on transport: An overview of empirical findings. Transportation Research Part D: Transport and Environment, 14(3), 205-221. doi:10.1016/j.trd.2008.12.004

Kwakkel, Jan H., \& Pruyt, Erik (2013). Exploratory modeling and analysis, an approach for model-based foresight under deep uncertainty. Technological Forecasting and Social Change, 80(3), 419-431.

Lambert, J. H., Wu, Y.-J., You, H., Clarens, A., \& Smith, B. (2013). Climate change influence to priority setting for transportation infrastructure assets. Journal of Infrastructure Systems, 19(1), 36-46. doi:10.1061/(ASCE)IS.1943555X.0000094

Lempert, R., Nakicenovic, N., Sarewitz, D., \& Schlesinger, M. (2004). Characterizing climate-change uncertainties for decision-makers. An editorial essay. Climatic Change, 65(1), 1-9.

Mohor, G. S., Rodriguez, D. A., Tomasella, J., \& Júnior, J. L. S. (2015). Exploratory analyses for the assessment of climate change impacts on the energy production in an Amazon run-of-river hydropower plant. Journal of Hydrology: Regional Studies, 4, 41-59.

Mostafavi, Ali, Abraham, Dulcy M., DeLaurentis, Daniel, \& Sinfield, Joseph (2011). Exploring the dimensions of systems of innovation analysis: A system of systems framework. IEEE Systems Journal, 5(2), 256-265.

Mostafavi, A., Abraham, D. M., \& Lee, J. (2012). System-ofsystems approach for assessment of financial innovations in infrastructure. Built Environment Project and Asset Management, 2(2), 250-265.

Mostafavi, A., Abraham, D., \& DeLaurentis, D. (2013). Ex-ante policy analysis in civil infrastructure systems. Journal of Computing in Civil Engineering, 28(5), A4014006.

Mostafavi, A., Abraham, D., DeLaurentis, D., Sinfield, J., Kandil, A., \& Queiroz, C. (2015). Agent-based simulation model for assessment of financing scenarios in highway transportation infrastructure systems. Journal of Computing in Civil Engineering, 30(2), 04015012.

O’Rourke, T. D. (2007). Critical infrastructure, interdependencies, and resilience. BRIDGE-WashingtonNational Academy of Engineering-, 37(1), 22.

Ortiz-García, J. J., Costello, S. B., \& Snaith, M. S. (2006). Derivation of transition probability matrices for pavement deterioration modeling. Journal of Transportation Engineering, 132(2), 141-161.

Ostrom, E. (2007). A general framework for analyzing sustainability of. In Proceedings of the Royal Society of London, Series B, 274, 1931.

Ouyang, M., Dueñas-Osorio, L., \& Min, X. (2012). A threestage resilience analysis framework for urban infrastructure systems. Structural Safety, 36, 23-31.

Parmesan, C. (2006). Ecological and evolutionary responses to recent climate change. Annual Review of Ecology, Evolution, and Systematics, 637-669.

Patt, A., \& Siebenhüner, B. (2005). Agent based modeling and adaptation to climate change. Vierteljahrshefte zur Wirtschaftsforschung, 74(2), 310-320. doi:10.3790/ vjh.74.2.310

Rashedi, R., \& Hegazy, T. (2015). Holistic analysis of infrastructure deterioration and rehabilitation using system dynamics. Journal of Infrastructure Systems, 22(1), 04015016.

Reed, D. A., Kapur, K. C., \& Christie, R. D. (2009). Methodology for assessing the resilience of networked infrastructure. IEEE Systems Journal, 3(2), 174-180.

Rehan, R., Knight, M. A., Haas, C. T., \& Unger, A. J. A. (2011). Application of system dynamics for developing financially self-sustaining management policies for water and wastewater systems. Water Research, 45(16), 4737-4750.

Rinaldi, S. M. (2004). Modeling and simulating critical infrastructures and their interdependencies. In 37th Annual Hawaii International Conference on System Sciences. IEEE. doi:10.1109/HICSS.2004.1265180

Sanford Bernhardt, K. L., \& McNeil, S. (2008). Agentbased modeling: Approach for improving infrastructure management. Journal of Infrastructure Systems, 14(3), 253-261.

Shortridge, J., Guikema, S., \& Zaitchik, B. (2017). Robust decision making in data scarce contexts: Addressing data and model limitations for infrastructure planning under transient climate change. Climatic Change, 140(2), 323-337. 
Southeast Florida Regional Climate Compact (SFRCC). (2011). Aunifiedsealevelriseprojection forSoutheastFlorida. Retrieved 2015, from http://www.southeastfloridaclimatecompact. org/wp-content/uploads/2015/10/2015-Compact-UnifiedSea-Level-Rise-Projection.pdf

Thomas, W. H., North, M. J., Macal, C. M., \& Peerenboom, J. P. (2003). Complex adaptive systems representation of infrastructure interdependencies (pp. 58-67). Dahlgren, VA: Naval Surface Warfare Center Technical Digest, Naval Surface Warfare Center.
Winkler, J., Dueñas-Osorio, L., Stein, R., \& Subramanian, D. (2010). Performance assessment of topologically diverse power systems subjected to hurricane events. Reliability Engineering \& System Safety, 95(4), 323-336. doi:10.1016/j. ress.2009.11.002

Xu, M., Weissburg, M., Newell, J. P., \& Crittenden, J. C. (2012). Developing a science of infrastructure ecology for sustainable urban systems. Environmental Science \& Technology, 46(15), 7928-7929. 